\title{
鴒 New Disease Reports \\ Emerging threat of Sclerotinia sclerotiorum causing white/cottony stem rot of mesta in India
}

\author{
A.N. Tripathi ${ }^{1 *}$, R.K. De ${ }^{1}$, H.K. Sharma ${ }^{2}$ and P.G. Karmakar ${ }^{2}$ \\ ${ }^{1}$ Division of Crop Protection, ICAR - Central Research Institute for Jute and Allied Fibres, Barrackpore, Kolkata, India - \\ 700120; ${ }^{2}$ Division of Crop Improvement, ICAR - Central Research Institute for Jute and Allied Fibres, Barrackpore, Kolkata, \\ India - 700120 \\ *E-mail: antripathi_patho@rediffmail.com
}

Received: 03 Sep 2015. Published: 13 Nov 2015. Keywords: Hibiscus, fungal plant disease, sclerotia

Mesta (Hibiscus sabdariffa and H. cannabinus, Malvaceae) is considered the third most important commercial crop in bast fibre production. Over the last three years, disease has become a major emerging threat to cultivation of mesta for commercial seed production. During December and January of 2012-14, a stem rot was noted in the seed crop of mesta with a disease incidence up to $50 \%$ at the CRIJAF Research Farm in Barrackpore, West Bengal, India. Initial disease symptoms appeared in the form of water-soaked lesions on the stem resulting in eventual dieback of the plant during the capsule and boll formation stages. Lesions of infected stems and bolls usually developed patches of white, fluffy mycelial mats often with large, irregular, black-coloured sclerotia, typical of Sclerotinia sclerotiorum.

Infected plants were collected and the diseased stem tissue was surface sterilised for one minute in $1 \%$ mercuric chloride. The stem pieces were plated on potato dextrose agar (PDA) and incubated at $20 \pm 2^{\circ} \mathrm{C}$ for 10 days. After incubation, all colonies recovered produced abundant, irregular, large, black-coloured sclerotia $(0.5-1.5 \mathrm{~cm})$ on PDA. Germinated sclerotia produced white-coloured colonies with hyaline, septate, branched hyphae. The isolated fungus was identified as $S$. sclerotiorum based on morphological and cultural characteristics of the mycelia and sclerotia (Purdy, 1979; Willets \& Wong, 1980; Bolton et al., 2006).

To fulfil Koch's postulates, mycelial plugs ( $5 \mathrm{~mm}$ diameter), obtained from 10-day-old cultures grown on PDA, were dipped in a $1 \%$ gelatin solution and placed on the wounded stem of three two-month-old healthy mesta plants (var. CRIJAF-R-2). Control plants were treated similarly but were inoculated with a plug of sterile PDA. The wounded portion of the stem was wrapped with plastic film. All the inoculated and control test plants were kept in the greenhouse for observation. Inoculated mesta plant developed lesions within $15-20$ days after incubation at $20^{\circ} \mathrm{C}$ followed by the appearance of white mycelia and sclerotia on the stem. Plants showed dieback symptoms similar to those originally observed in the field. $S$. sclerotiorum was re-isolated from the infected stems of inoculated mesta plants and identified morphologically. Control plants remained symptomless and the pathogen was not recovered.

Sclerotinia sclerotiorum causes disease on a wide range of economically important plants throughout the world but very little information is available with reference to mesta. White/cottony stem rot is a serious limiting factor for mesta seed production due to the ineffectiveness of available control measures. In 1934, Mundkur reported this is an important disease of mesta. Tripathi et al. $(2013,2014)$ also observed Sclerotinia stem rot as a serious threat to mesta seed crops, however, jute and flax seed crops planted in the same spot were free from this disease. Currently, commercial mesta seed production is gaining acceptance among farmers compared to earlier practices of growing mesta only as a fibre crop. This report highlights the emergence of this pathogen in North East India and the importance of developing disease-free plants for conservation and exchange of germplasm for crop improvement under the International Plant Protection Convention, as well as management of the disease under a changing climatic scenario.

\section{Acknowledgements}

The authors acknowledge the research facilities provided by the Director, ICAR - Central Research Institute for Jute and Allied Fibres, Barrackpore, Kolkata.

\section{References}

Bolton MD, Thomma BPHJ, Nelson BD, 2006. Sclerotinia sclerotiorum (Lib.) de Bary: Biology and molecular traits of a cosmopolitan pathogen. Molecular Plant Pathology 7, 1-16. http://dx.doi.org/10.1111/j.1364-3703.2005.00316.x

Mundkur BB, 1934. A Sclerotinia rot of Hibiscus sabdariffa. Indian Journal of Agricultural Science 4, 758-778.

Purdy LH, 1979. Sclerotinia sclerotiorum: history, diseases and symptomatology, host range, geographic distribution, and impact. Phytopathology 69, 875-880. http://dx.doi.org/10.1094/Phyto-69-875

Tripathi AN, Sarkar SK, Sharma HK, Karmakar PG, 2013. Stem rot of roselle: A major limitation for seed production. JafNews 11, 14.

Tripathi AN, Sarkar SK, Sharma HK, Karmakar PG, 2014. Detection and characterization of roselle stem rot pathogen, Sclerotinia sclerotiorum (Lib.) de Bary and its sensitivity towards bioagents. National Symposium on Plant Pathology in Genomic Era, 2014, Department of Plant Pathology, Indira Gandhi Krishi Vishwavidyalay Raipur, Chhattisgarh, India, 8-9.

Willetts HJ, Wong JAL, 1980. The biology of Sclerotinia sclerotiorum, S. trifoliorum, and S. minor with emphasis on specific nomenclature. The Botanical Review 46, 101-165. http://dx.doi.org/10.1007/BF02860868

To cite this report: Tripathi AN, De RK, Sharma HK, Karmakar PG, 2015. Emerging threat of Sclerotinia sclerotiorum causing white/cottony stem rot of mesta in India. New Disease Reports 32, 19. http://dx.doi.org/10.5197/j.2044-0588.2015.032.019

c) 2015 The Authors This report was published on-line at www.ndrs.org.uk where high quality versions of the figures can be found. 